\title{
ASPECTOS DO CLIMA URBANO DE CURITIBA/PR: UMA ABORDAGEM DO CAMPO TÉRMICO E SUA INFLUÊNCIA SOBRE A OCORRENCIA DA DENGUE
}

\author{
Kauan Arthur Fonseca Lunardon (a) \\ (a) Departamento de Geografia, Universidade Federal do Paraná, kauanfoseca@ufpr.br
}

Eixo: Climatologia em diferentes níveis escalares: mudanças e variabilidades

\begin{abstract}
Resumo
Entendendo as características ambientais enquanto condicionantes ou limitantes à proliferação de determinadas patologias, esta pesquisa de Iniciação Científica, inserida dentro do projeto "Clima urbano e dengue nas cidades brasileiras", pretendeu analisar a dinâmica da dengue em relação ao campo térmico de Curitiba, partindo da identificação de condicionantes propícias para o aparecimento de focos do vetor. Com a utilização de dados da temperatura do solo obtidas através do sensor MODIS, foi possível a identificação de ilhas de calor, passíveis de intensificação em alguns cenários de mudança do clima em escala global e local. A espacialização dessas condições permitiu analisar quais áreas da cidade apresentaram temperaturas mais elevadas, evidenciando gradientes de temperatura de até $8^{\circ} \mathrm{C}$ no perímetro urbano da cidade. Verificou-se em determinadas zonas, a presença de condicionantes ambientais e sociais propicias ao aparecimento de focos de Aedes Aegypti, o que ressalta a importância de ações de enfrentamento nas mesmas.
\end{abstract}

Palavras chave: Dengue, Clima Urbano, Clima e saúde, Campo Térmico.

\section{Introdução}

O espaço afeta a saúde dos indivíduos de diversas maneiras, sendo que o clima se coloca como um dos elementos ambientais que a influenciam diretamente (MENDONÇA, 2001). De acordo com Rouquayrol, os aspectos climáticos que mais afetam os indivíduos, no que tange ao processo de transmissão de doenças são a temperatura do ar, a umidade relativa e a precipitação pluviométrica (ROUQUAYROL,1999 apud PAULA, 2005). Esse trabalho voltará suas atenções para o primeiro elemento citado, compreendido dentro Campo Termodinâmico do Sistema Clima Urbano proposto pelo prof ${ }^{\circ}$ Carlos A. F. Monteiro (1976).

A dengue é uma enfermidade recorrente na maior parte do Brasil, bem como em vários países do mundo tropical, o que se deve a presença de condições ambientais propícias somadas a diversas situações de vulnerabilidade causadas pelo modo como se deu o desenvolvimento urbano aqui ocorrido. S Segundo Sabroza (2005 apud OLIVEIRA, 2006, p. 07), a dengue "apresenta-se como uma doença emergente, 
oferecendo riscos imediatos à população do espaço urbano, sobretudo, pela urbanização acentuada, pelo aumento da densidade populacional, e pela situação socioeconômica que está vinculada à expectativa de vida”. Frisa-se que a problemática atualmente se agrava ao passo que o vetor dessa enfermidade tem se mostrado capaz de transmitir outras doenças, como a Chikungunya e o Zika Vírus.

No caso da dengue, bem como das outras doenças metaxênicas, isto é, aquelas que exigem para a sua propagação vetores biológicos, o clima se coloca não só como fator limitante do vetor em escala global, mas também influência sua propagação em escala local e regional, tendo principalmente a temperatura e a precipitação como fatores limitantes (JOHANSSON, 2009 apud ROSEGHINI, 2013). Este trabalho voltase para a escala regional, compreendida pelo município de Curitiba.

\section{Materiais e métodos}

Primeiramente, buscou-se definir um recorte temporal. Foram escolhidos os meses de Janeiro, Fevereiro e Março de 2016, por apresentarem-se, pela série histórica como os mais propensos a ocorrência de dias com risco médio e alto para a proliferação do mosquito, com base em informações retiradas do banco de dados do SACDengue ${ }^{1}$. A ocorrência de situações de El Niño se mostraram em correlações anteriores como favoráveis a ocorrência de dias com risco elevado, fenômeno que se repetiu nos meses analisados.

Os dados que possibilitaram o estudo do campo térmico, com a identificação da distribuição espacial das ilhas de calor em Curitiba, foram obtidos e tratados através da plataforma IRI/LDEO Climate Data Library, oferecida pelo Instituto Internacional de Pesquisa em Clima e Sociedade (IRI) da Universidade de Columbia (EUA). Esses dados, por sua vez, foram colhidos pelo sensor MODIS (Moderate-resolution Imaging Spectroradiometer), lançado pela NASA em 2002 e atualmente em órbita na Terra, a bordo do satélite Acqua. O sensor tem a capacidade de capturar dados em 36 diferentes bandas espectrais, o que nos permitiu a identificação, dentre outras informações, a temperatura do solo em uma escala espacial de 1000 metros.

Muito embora, entendendo as problemáticas derivadas da atribuição de uma ilha de calor apenas pela temperatura do solo, que normalmente se diferencia da temperatura do ar, a escolha da primeira se respaldou nas possibilidades práticas do levantamento e da análise dos dados, bem como na grande relevância dessa variável na própria ecologia do vetor estudado. A espacialização gerada na plataforma do

\footnotetext{
${ }^{1}$ Sistema de Alerta Climático para Dengue, projeto desenvolvido pelo Laboratório de Climatologia da Universidade Federal do Paraná, que elabora semanalmente um índice de riscos climáticos, com relação à dengue, para 18 cidades paranaenses, com base em dados horários de temperatura, precipitação e umidade relativa do ar (MENDONÇA et al, 2011).
} 
IRI/LDEO, foi georeferenciada com o auxílio do Quantum GIS, o que permitiu um reconhecimento mais aprimorado dos bairros e regiões da cidade.

\section{Resultados e discussões}

Como encontrado em parte anterior dessa investigação, percebeu-se uma grande relevância das temperaturas mínimas para a ocorrência de dias propícios para a proliferação do vetor da dengue. Ao passo que uma diferença de 2 a 3 graus célsius, como a encontrada entre as áreas mais críticas da ilha de calor em relação a seu entorno, é suficiente para a manifestação de um risco mais elevado.

Dessa forma, atribuiu-se para as áreas, onde a ocorrência da ilha de calor é mais intensa, como mais propícias a ocorrência e proliferação do Aedes Aegypti. É de valia citar que tal situação não é via de regra para todas as cidades, já que muitas vezes a ocorrência de temperaturas mais elevadas que o normal em decorrência do impacto urbano pode ser prejudicial para o vetor. No entanto, devido as condicionantes climáticas de Curitiba, não favoráveis ao mesmo, o que ocorre é o oposto.

A constatação de temperaturas mais elevadas nos bairros centrais, e próximos do centro não foi surpresa. Características dessa região, como alta densificação urbana, verticalização e impermeabilização solo, são condicionantes que indicam tal comportamento, o que por outro lado não indicam situações socioespaciais favoráveis a criação de focos de dengue. Da mesma forma, as ocupações mais periféricas, vítimas da injustiça ambiental, localizadas próximas de rios, com presença de depósitos de lixo e entulhos, apresentam condicionantes socioambientais mais propensos a criação de possíveis focos. Quando as duas situações (risco térmico e socioespacial) ocorrem de forma concomitante, áreas mais vulneráveis são evidenciadas.

Como se evidencia na figura 1, para o mês de janeiro, a ilha de calor se mostrou bastante intensa e concentrada no centro da cidade e nos bairros em seu entorno, se estendendo para os bairros mais ao sul Xaxim, Hauer, Lindóia e Fanny, de características residenciais, e bastante adensados. Outra ilha se manifestou com expressividade também no sul da Cidade Industrial de Curitiba (CIC), na porção oeste da cidade.

Em fevereiro, percebeu-se a presença da ilha de calor com intensidade sob toda a região centro e norte da cidade, com destaque para os bairros São Miguel, Capão Raso, Novo Mundo e a parte sul da CIC. Temperaturas menos elevadas foram encontradas apenas nos bairros mais ao sul, como Caximba, Campo de Santana e Umbará, com até $06^{\circ} \mathrm{C}$ a menos que a região central. 

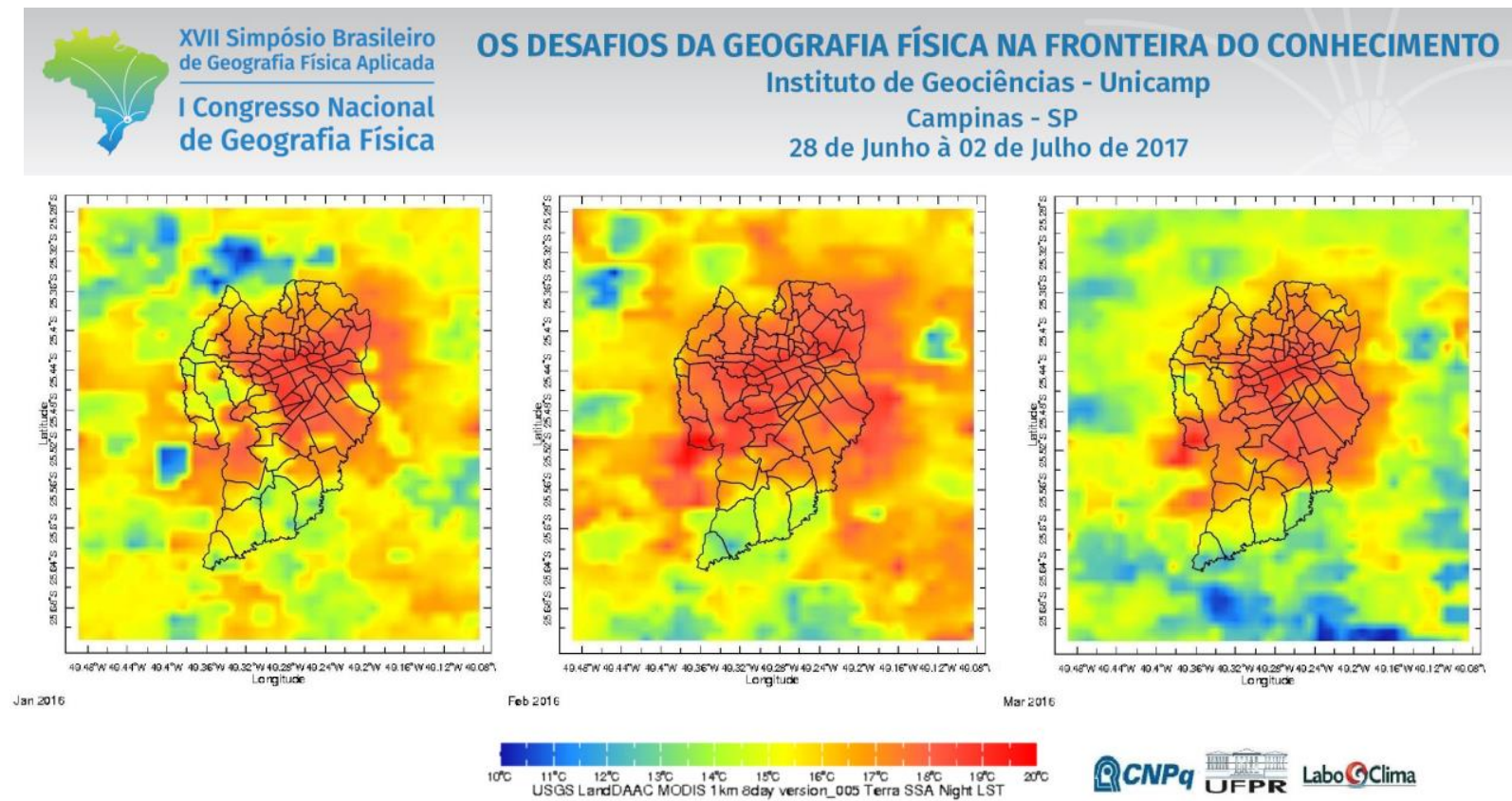

Figura 1: Espacialização das ilhas de calor no município de Curitiba, para os meses de Janiero, Fevreriro e Março de 2016. Elaborado pelo autor.

No mês de março, os bairros centrais e pericentrais mostraram-se como mais atingidos pela ilha de calor, bem como novamente o bairro São Miguel, na região oeste e os bairros Boqueirão, Uberaba e Cajuru, na porção leste da cidade. A parte oeste da cidade, demarcada pela Cidade Industrial e seu entorno aparece enquanto uma região que reúne tanto fatores climáticos favoráveis a propagação de dengue, quanto sócio espaciais. A presença de uma grande concentração industrial nessa área do município se refletiu nas imagens de satélite com a manifestação de ilha de calor de mesma intensidade da encontrada na região central, porém com características socioespaciais (terrenos baldios, deposito de lixo a céu aberto) mais propícias a ocorrência de focos do mosquito Aedes Aegypti, sendo então uma região que deve ser foco de atenção.

Embora a pesquisa não esteja concluída, a espacialização das condições térmicas, apesar de episódicas permitiram analisar quais áreas da cidade apresentaram temperaturas mais elevadas, ressaltando gradientes de temperatura de até $8^{\circ} \mathrm{C}$ no perímetro urbano da cidade. Verificou-se em certas áreas a presença de condicionantes ambientais e sociais propicias ao aparecimento de focos de Aedes Aegypti, o que ressalta a importância de ações de enfrentamento nessas áreas.

Pretende-se nas próximas etapas, aprimorar o entendimento sobre as condicionantes que estruturam as diferentes situações de vulnerabilidade com relação a dengue e outras patologias transmitidas pelo mesmo vetor, focalizando mais as de ordem socioespacial. Para assim, juntamente com as evidências de ações de enfrentamento vigentes, esboçar um quadro geral da vulnerabilidade à dengue para o município de Curitiba. 


\section{Bibliografia}

AQUINO JUNIOR, José. A dengue na área urbana contínua de Maringá/PR: uma abordagem socioambiental da epidemia 2006/07. 2010. 188f. Dissertação (mestrado) - Universidade Federal do Paraná, Setor de Ciencias da Terra, Programa de Pós-Graduaçao em Geografia. Defesa:Curitiba, 15/04/2010.

COLÓN- GONZALES, F., FEZZI, C., LAKE, I., HUNTER, P. The Effects of Weather and Climate Change on Dengue. PLoS Neglected Tropical Diseases, vol. 7(11): nov. 2013, p. e2503.

HALES, Simon et. al. Potential effect of population and climate changes on global distribuition of dengue fever: an empirical model. The Lancet, vol. 360, set., 2002, p. 830-834.

JOHANSSON, Michael; DOMINICI, Francesca e GLASS, Gregory. Local and Global Effects of Climate on Dengue Transmission in Puerto Rico. Neglected Tropical Diseases, vol 3, Issue 2, feb. 2009, pag. e382.

MENDONÇA, Francisco de Assis. Clima e criminalidade: ensaio analitico da correlação entre a temperatura do ar e a incidencia de criminalidade urbana. Curitiba: Ed. UFPR, 2001. 181p

MENDONCA, F. A. ; ROSEGHINI, W. F. F. ; AQUINO JR, J. ; CASTELHANO, F. J. ; HOFFMAN, T. C. P. . SACDENGUE: Systeme d'Alerte Climato-Meteorologique de Prevention de L'epidemie de Dengue (Bresil). In: XXIV Colloque de L'association Internationale de Climatologie, 2011, Rovereto/Italia. Actes du XXIV Colloque de l'Association Internationale de Climatologie. Ferrara/Italia: Universita de Ferrara, 2011. v. 1. p. 411-416.

MORIN, C., COMRIE, A., ERNST, K. Climate and Dengue Transmission: Evidence and Implications. Environmental Health Perspectives, volume 121 | number 11-12 | November-December 2013, P. 1264-1272.

NOAA. Cold e warm episodes by season. Disponível em: <http://www.cpc.noaa.gov/products/ analysis_monitoring/ensostuff/ensoyears.shtml>. Acesso em 24/02/2016.

OLIVEIRA, Marcia Maria Fernandes de. Condicionantes sócio-ambientais urbanos da incidência da dengue na cidade de Londrina - PR. 2006. xvi, 150f. Dissertação (mestrado) - Universidade Federal do Paraná, Setor de Ciencias da Terra, Programa de Pós-Graduaçao em Geografia. Defesa: Curitiba, 2006.

PAULA, Eduardo Vedor de. Dengue: uma análise climato- geográfica de sua manifestaçao no estado do Paraná (1993-2003). 2005. x, 164f. Dissertaçao (mestrado) - Universidade Federal do Paraná, Setor de Ciencias da Terra, Programa de Pós-Graduaçao em Geografia. Defesa: Curitiba, 2005.

ROJAS, Luisa Iñiguez. Geografía y salud: temas y perspectivas en América Latina. Cad. Saúde Pública, Rio de Janeiro, 14(4), out-dez, 1998, p. 701-711.

ROSEGHINI, Wilson Flávio Feltrim. Clima urbano e dengue no centro-sudoeste do Brasil. Tese (doutorado) Universidade Federal do Paraná, Setor de Ciências da Terra, Programa de Pós-Graduação em Geografia. Defesa: Curitiba, 22/03/2013.

WHO, Word Health Organization. Global alert and response. Dengue/dengue hemorrhagic fever. Disponível em: $<$ http://www.who.int/csr/disease/dengue/en> Acesso em Janeiro de 2016. 